\title{
CORRECTION
}

\section{Correction: Interleukin-22-deficiency and microbiota contribute to the exacerbation of Toxoplasma gondii-induced intestinal inflammation}

A Couturier-Maillard ${ }^{1}$, N Froux ${ }^{2}$, J Piotet-Morin ${ }^{1}$, C Michaudel ${ }^{1}$, L Brault ${ }^{1}$, J Le Bérichel ${ }^{1}$, A Sénéchal ${ }^{2}$, P Robinet ${ }^{1}$, P Chenuet ${ }^{1}$, S Jejou ${ }^{3}$, L Dumoutier $^{4}$, J C Renauld ${ }^{4}$, J lovanna ${ }^{5}$, S Huber ${ }^{6}$, M Chamaillard ${ }^{7}$, V F J Quesniaux ${ }^{1}$, H Sokol $^{3,8,9}$ and B Ryffel $^{1}$

Mucosal Immunology (2019) 12:290; https://doi.org/10.1038/s41385-018-0112-6

Correction to: Mucosal Immunology; https://doi.org/10.1038/ s41385-018-0005-8; published online 04 May 2018.

The original version of this Article omitted the author Dr Mathias Chamaillard from the I'Institut de Pasteur, Lille, France.
This has been corrected in both the PDF and HTML versions of the Article.

\footnotetext{
${ }^{1}$ Laboratory of Experimental and Molecular Immunology and Neurogenetics (INEM), CNRS and University of Orleans (UMR7355), Orléans, France; ${ }^{2}$ CNRS UPS44 -TAAM, Orléans,

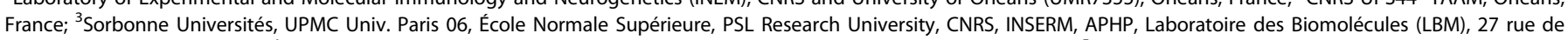

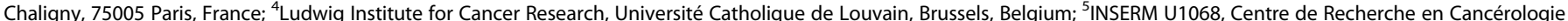

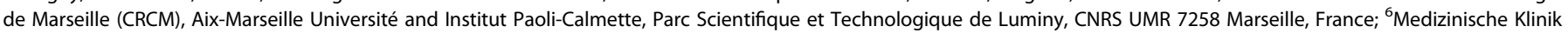

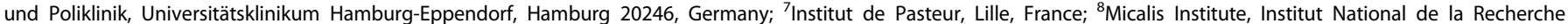

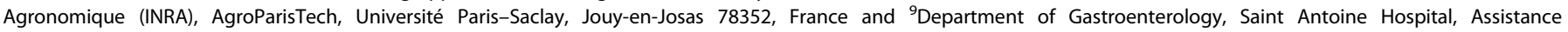
Publique-Hopitaux de Paris, UPMC, Paris, France

Correspondence: B Ryffel (bryffel@cnrs-orleans.fr)

These authors contributed equally: H Sokol, B Ryffel
}

Published online: 30 November 2018 